\title{
Dissociation between speech modalities in a case of altered accent with unknown origin
}

\section{Nicola Bessella , Jennifer M Gurd ${ }^{b}$ and John Colemanc}

\author{
aspeech and Hearing Sciences, BHSC, University College Cork National University of \\ Ireland, Cork, Ireland; \\ ${ }^{\mathrm{b}}$ Nuffield Department of Clinical Neurosciences, University of Oxford, Oxford, United \\ Kingdom of Great Britain \\ and Northern Ireland; 'Oxford University Phonetics Laboratory, Oxford, United Kingdom of \\ Great Britain and Northern Ireland
}

\section{To appear in Clinical Linguistics and Phonetics}

https://doi.org/10.1080/02699206.2019.1624827

\begin{abstract}
We present a case of sudden onset, acquired altered accent in the speech of NL, a 48 year old, left-handed female. NL's typical Standard Southern British English accent was preserved in singing and reading, but altered in recitation, repetition and spontaneous speech. Neuropsychological investigation, impressionistic and acoustic analysis of accented and unaccented speech are documented. The altered accent displays a slower speech rate and longer duration of consonants and vowels. There is evidence for a shift towards syllable-timed rhythm. NL's altered accent displays atypical coordination between voicing and supra-laryngeal articulation, reduced mean and range of F0, and minor differences in vowel space. These features are broadly consistent with other documented cases of Foreign Accent Syndrome, regardless of etiology. However, NL's profile of preserved and impaired speech does not fit any pattern typically associated with organic neurological disorder. Moreover left-handed preference may contribute to differences between singing and reading, versus recitation, repetition and spontaneous speech.
\end{abstract}


KEYWORDS: speech disorders, adult, acoustic analysis, non-organic, altered accent 


\section{INTRODUCTION}

Acquired altered accent, also termed acquired foreign accent or most commonly, Foreign Accent Syndrome (FAS), is a disorder in which the speech of a native language user is perceived by listeners as having a non-native or foreign sounding accent. FAS presents uniquely in each patient; frequently shared features include altered prosody as well as altered quality and duration of consonants and vowels (Coelho \& Robb, 2001; Gurd, Bessell, Bladon \& Bamford, 1988; Keulen \& Verhoeven et al., 2016; Moen, 2000; Perkins \& Ryalls, 2013; Ryalls \& Miller, 2014).

Documented cases of FAS are relatively uncommon ( $c f$. Gurd \& Coleman, 2006), but in the last few decades FAS has received considerable attention and the number of reported cases in the literature has increased considerably (Haley, Roth, Helm-Estabrooks \& Thiessen, 2010). Keulen and Verhoeven et al. (2016) identify a total of 105 cases from literature published between 1907 and 2014. Miller (2007) notes that FAS can be a transitory stage in recovery from the triggering event and is probably underreported overall.

The most common cause of FAS is neurological injury or disturbance, primarily left-hemisphere stroke (Blumstein, Alexander, Ryalls, Katz \& Dworetzky, 1987; Gurd et al., 1988; Moen, 2000). A smaller number of cases are linked to traumatic brain injury (Lippert-Gruener, Weinert, Greisbach \& Wedekind, 2005; Monrad-Krohn, 1947; Moonis et al., 1996), multiple sclerosis (Bakker, Apeldoorn \& Metz, 2004; Chanson, Kremer, Blanc, Marescaux, Namer \& de Seze, 2009) and most recently, developmental disorders (Keulen \& Mariën et al., 2016). 
Early work adopted a definition of FAS that required a neurogenic origin (Whitaker, 1982), but subsequent research has identified cases of apparently non-organic or psychogenic FAS (Gurd, Coleman, Costello \& Marshall, 2001; Reeves, Burke \& Parker, 2007; Haley et al., 2010). In their literature review Keulen and Verhoeven et al. (2016: 2) identify 15 of 105 cases (14\%) as psychogenic FAS, a categorisation prompted when 'medical history, onset of symptoms, symptom characteristics and their evolution, neurological examinations, neuroimaging and cognitive workup do not point unambiguously toward a neurological disorder.' Verhoeven and Mariën (2010) note the possibility of mixed neurogenic and psychogenic etiologies for some cases of FAS (where, for example, psychogenic symptoms may be overlaid on those associated with neurological disorder or injury).

Disrupted prosody (local and global pitch characteristics, intonation, rhythm and timing) is often considered a core feature of FAS (Aronson, 1980; Blumstein \& Kurowski, 2006; Coelho \& Robb, 2001). Atypical timing and rhythm are widely reported, with corresponding effects on perceived duration and stress (Blumstein \& Kurowski, 2006). A tendency towards syllable-timing, equal stress or staccato rhythm is reported for much, but not all, FAS speech (Berthier, Ruiz, Massone, Starkstein, \& Leiguarda, 1991; Blumstein et al., 1987; Gurd et al., 2001; Jonkers, van der Scheer \& Gilbers, 2016; Roy, Macoir, Martel-Savageau \& Boudreault 2012; Varley, Whiteside, Hammil \& Cooper, 2006). In terms of speech rate, FAS speech is often reported to be slow (Coelho \& Robb, 2001; Katz, Garst \& Levitt, 2008; Keulen \& Verhoeven et al., 2016; Kurowski, Blumstein \& Alexander, 1996), but there are cases with faster rates (Lewis, Ball \& Kitten, 
2012) or no difference from control data (Dankovičová, Gurd, Marshall, MacMahon, Stuart-Smith, Coleman \& Slater, 2001; Haley et al., 2010).

Other non-segmental features of FAS include higher average pitch (Coelho \& Robb, 2001; Miller, Lowit \& O’Sullivan, 2006; Ryalls \& Whiteside, 2006) but also creaky voice and lower mean F0 (Verhoeven \& Mariën, 2010). Pitch range and excursions are reported unaffected (Gurd et al., 1988), large (Moonis et al., 1996), inappropriate (Blumstein et al., 1987) and/or reduced (Verhoeven \& Mariën, 2010).

Although both vowels and consonants can be altered in FAS, the literature appears to indicate that vowels are typically more affected than consonants (Aronson, 1980; Katz et al., 2008; Miller et al., 2006; Moen, 2000). It is not always clear whether differences in both duration and quality contribute to this assessment or whether quality alone is referred to while variation in vowel duration comes under prosodic disturbance. Vowel duration in FAS is varied. It can be typical (Blumstein et al., 1987), longer (Graff-Radford, Cooper, Colsher \& Damasio 1986; Miller et al., 2006) or shorter (Ingram, McCormack, \& Kennedy, 1992; Perkins, Ryalls, Carson, \& Whiteside, 2010). In terms of quality, FAS vowels are reported as overall more peripheral and often more tense though of course duration is also a cue to the English tense/lax contrast (Blumstein et al. 1987; Graff-Radford et al., 1986; Katz et al., 2008). Blumstein et al. (1987) and Katz et al. (2008) report that unstressed FAS vowels tend not to reduce towards a more central position in their data. On the other hand, Coelho and Robb (2001) describe reduced range of both F1 and F2 in their survey. Likewise, Lewis et al. (2012) report overall 'condensing' of the vowel space. 
Vowel quality can also remain unaffected (Katz et al., 2008; Laures-Gore, Henson, Weismer \& Rambow, 2006).

Altered voicing, place of articulation changes and manner changes have all been described for consonant articulation in FAS (Dankovičová \& Hunt, 2011; Katz et al., 2008; Verhoeven \& Mariën, 2010 provide numerous references). Prevoicing of consonants and changes in Voice Onset Time (VOT) both indicate disrupted timing of laryngeal and supralaryngeal articulation and are widely attested. Changes in manner (both fortition and lenition processes) are considered the most common supralaryngeal consonantal changes (Coelho \& Robb, 2001; Moen, 2000).

On every measure, both suprasegmental and segmental, there is considerable heterogeneity in the presentation of FAS speech. What remains consistent is the perception of foreignness rather than disorder (Di Dio, Shultz \& Gurd, 2006).

We present a new case of altered accent from a participant (NL) whose linguistic profile shows impaired spontaneous speech, oral recitation and repetition, but normal pronunciation in reading and singing. Clearly, NL's motoric ability to produce typical speech remains intact, but the dissociation between reading and singing on the one hand and spontaneous speech, recitation and repetition on the other, is totally unexpected. Although singing is known to facilitate unaccented speech in patients with non-fluent aphasia (Yamadori, Osumi, Masahura \& Okubo, 1977) and the same has been reported for FAS (Laures-Gore et al., 2006), the combination of unaccented singing and reading as opposed to accented spontaneous speech, repetition and recitation has not been reported before. As a result, NL's unique presentation defies 
categorization given our current state of theoretical and clinical knowledge. Such cases warrant attention because they present a clinical as well as a theoretical dilemma: it is difficult to determine therapeutic needs or justify choice of care pathways without a clear diagnosis. In addition, this unique pattern of dissociation is, in NL's case, combined with no clear evidence for organic cause.

We were able to spend approximately three hours with NL for both neuropsychological and linguistic investigation. In view of these limitations of time we are unable to develop a rigorous hypothesis led investigation and instead obtain as comprehensive a view of the case as possible. We present a post hoc analysis of speech data elicited in the course of exploratory investigations intended to assess NL's overall cognitive function, the general and specific qualities of her affected and unaffected speech, and the general circumstances under which each accent appeared. While the limited amount of test time restricts our exploration of some aspects of NL's speech, the highly unusual dissociation observed requires documentation for a.) substantiation and b.) to ground subsequent discussion.

Our aims are to provide a fine-grained description of NL's speech in both altered and unaltered conditions and compare the findings with what is known from other cases of FAS, regardless of etiology. This should establish the appropriateness, or not, of considering NL's accented speech within the category of FAS. In addition, we present cognitive and neuropsychological test data on NL. Such data is not available in all published case studies, yet it can contribute to diagnosis and etiology, neither of which are obvious in this particular case.

Based on impressionistic listening and NL's interactions with experienced researchers, we hypothesize that the features of NL's accented speech are within 
the parameters of published descriptions of FAS, despite the unusual dissociations observed. We discuss the results of acoustic investigation of NL's speech, neurocognitive testing and handedness as part of our consideration of these issues. With respect to etiology, NL's profile of preserved and altered speech is not consistent with cases with known neurological origin. In the absence of confirming evidence for organic etiology, consultant neurologists diagnosed NL's symptoms as psychogenic. With this in mind, we compare NL's data to a database of non-organic FAS (Keulen \& Verhoeven et al., 2016).

\section{METHODS}

Our study is a retrospective analysis of assessment data collected from a single participant presenting with speech difficulty of unknown origin. Ethical approval for research and data collection was obtained from COREC (Central Oxfordshire Regional Ethics Committee).

\section{Participant}

Participant NL was a left-handed 48-year old female, employed as a college lecturer. NL was born and has lived in the UK all her life. She learned French and German at school and has travelled widely in Europe. Her typical pre-onset dialect and accent is Standard Southern British English (SSBE). NL presented initially with a disorder of spoken language apparently related to a sudden onset headache six months earlier. She also reported several past concussions. The most recent one was eight years prior to the current incident and resulted in hospitalization. 
NL was assessed over a two-month period. During this time she complained of sudden onset left temporal headaches, variation in speech and motor abilities, and difficulty controlling her emotions. On initial assessment, NL spoke with an effortful altered accent and made unusual grammatical errors, particularly verb and verb tense errors in spontaneous speech, e.g. 'Ze make story will', 'When the shutdown comed the French seemed goned'. The latter comment was made as NL described how her ability to speak French was affected by the sudden onset of her speech difficulty. NL's accent was noted as German, Slavic or East European by some of the hospital staff with whom she came in contact. NL's spontaneous speech was further confused by articulatory problems (voicing errors, prolonged consonantal closure), anomia and circumlocution ('Alexander Graham Bell machine' for 'phone'), a suggestion of agrammatism or paragrammatism ('... depends the day really'; 'I really not know'), non-linguistic pauses often with 'mm' as a filler ('So mm mm just thinked mm ...') and some odd intonation patterns (particularly monotonal 'flat' intonation). These features completely disappeared in reading aloud, where the only indication of difficulty was restricted to the first few syllables, at which point NL switched into a fluent reading mode. In contrast to spontaneous speech, singing was also performed in a completely fluent and seemingly normal accent. In general NL's spontaneous speech and spoken recall tasks elicit what can be described as altered or foreign accented speech, whereas singing and reading tasks elicit speech with the speaker's typical, pre-onset SSBE accent.

\section{Materials}


NL completed the Hospital Anxiety and Depression Scale (HADS; Zigmund \& Snaith, 1983), the Paragraph Recall task from the Wechsler Memory Scale (Wechsler, 1987), digit span assessments, the Corsi Block test (Corsi, 1972), the Rey Figure Copy task (Rey, 1941), the Benton Visual Retention Test (Sivan, 1992), the Stroop Colour Test (Stroop, 1935), the Pyramids and Palm Trees Test (Howard and Patterson, 1992) and subtests from the Boston Diagnostic Aphasia Exam (Goodglass, 1983).

The Paragraph Recall task from The Wechsler Memory Scale tests logical memory. The subject is asked to retell a short story immediately after hearing it and then again after a set period of time. Tests of digit span recall assess shortterm memory and working memory. The Corsi Block Test assesses visuo-spatial short term memory by asking the subject to mimic an increasingly complex sequence of taps on identical, evenly spaced blocks. The Rey Figure Copy task presents a complex line drawing, asks the subject to copy the drawing and then thirty minutes later reproduce the drawing from memory. It assesses a number of cognitive abilities, the primary ones being visuo-spatial constructional ability and visual memory. The Benton Visual Retention Test measures visual perception and visual memory through brief presentation of designs that the subject then attempts to identify among competing options. The Stroop Colour Test assesses ability to inhibit cognitive interference during the processing of multiple features of a given stimulus (Scarpina \& Tagini, 2017). The Pyramids and Palm Trees Test assesses semantic processing. The Boston Diagnostic Aphasia Exam is an assessment for acquired aphasia and includes tasks that assess repetition, rhythm, recitation and naming. 
A single channel recording (sampling rate $44.1 \mathrm{kHz}, 16$ bits) of NL's speech was made in a sound insulated booth at the Oxford University Phonetics Laboratory using an Audio Technica AT4031 microphone, a Symetrics SX202 preamplifier and an HHB CDR850 professional compact disc recorder. NL was recorded reciting (RECITED) and then singing (SUNG) the nursery rhyme Baa Baa Black Sheep from memory. The RECITED and SUNG data share identical segmental targets, so this data is useful for comparison of many of the phonetic features of interest. However, since singing is governed by external demands of pitch and rhythm that can confound the comparison of text which is otherwise identical, we also analyse four read sentences which NL produced in an unaltered accent (READ). The four sentences match the four lines of the nursery rhyme in number of syllables. Finally, we provide data from a short sentence repetition task (REPEAT), also produced in an altered accent. Audio files of the nursery rhyme task (RECITED and READ) accompany this article.

\section{Procedures}

\section{Listener perception of accent}

To assess the perception of altered or foreign accent, we played the four tasks to a class of beginning undergraduate speech and language therapy students who had little first-hand experience of live disordered speech $(n=31)$. Students were given no information about the speaker(s). Students were played each sample one at a time and asked 'What do you notice about this person's speech?' They were then played each sample a second time and asked to identify the accent of the speaker(s). 


\section{Speech data analysis}

One author (NB) transcribed the four speech tasks using the International Phonetic Alphabet (IPA). The transcription was reviewed and agreed upon with minor edits by a second transcriber (JC). Speech data was analysed using the software package PRAAT (Boersma \& Weenink, 2014) and examined for formant values, fundamental frequency range, articulation rate, and durational features of words, as well as the consonants and vowels within each word. Segmental onset and offset were identified from the waveform and spectrograms, using commonly accepted procedures (Hieronymous, Alexander, Bennett, Cohen, Davies, Dalby, ... Wells, 1990), supplemented by listening where waveform and spectrographic cues were unclear. We use the Pairwise Variability Index (PVI; Low, Grabe and Nolan, 2000) to assess rhythmic aspects of NL's data.

We measured voicing during the stop closure of vowel-plosive transitions in SUNG and RECITED versions of the nursery rhyme. Consonantal closure is taken to be the period from loss of higher frequency formant structure at vowel offset to the burst of stop release. To evaluate vowel quality, first and second formant values were taken at the temporal midpoint of all monophthongs in all four conditions, using PRAAT's recommended settings for analysis of female voice. Formant tracking results were supplemented with narrow band spectra where necessary. Values for each vowel and condition were plotted using the NORM (Thomas \& Kendall, 2007) implementation of the Watt and Fabricius (2002) normalization method. This method allows a clear visual assessment of each vowel's distance from a centroid of the vowel space, regardless of the task from which the data originates. 
The average fundamental frequency of each vowel in all conditions was measured using PRAAT's pitch tracking algorithm with the range set at 100-500 $\mathrm{Hz}$, using the autocorrelation analysis method (40 ms analysis window) and averaging over the duration of the vowel. Pitch tracks for each breath group were also generated.

The interpretation of statistical analysis (paired two-tailed t-tests) of the SUNG and RECITED nursery rhyme data is subject to a Bonferroni correction of $.05 / 6$, with the result that $\mathrm{p} \leq .008$ is the corrected significance level, equivalent to uncorrected $\mathrm{p} \leq .05$. The READ and REPEAT data are not included in statistical analysis.

\section{RESULTS AND DISCUSSION}

\section{Assessment results}

The results of cognitive and neurolinguistic testing are summarized in table 1.

Table 1 about here.

NL's scores for the Hospital Anxiety and Depression Scale (HADS) are within the normal range for depression but abnormal (first testing) and borderline-abnormal (second testing) for anxiety. Tests of memory show mixed results. NL was unimpaired in both tasks on Paragraph Recall from the Wechsler Memory Scale. NL's forward digit span was within normal range whereas her backward digit span was slightly lower than expected given her forward span. NL's Corsi span was within normal limits. NL was impaired on both the copy and the recall of the Rey Figure Copy task (Rey, 1941). In the Benton Visual 
Retention Test NL scored 8 rather than the expected 10, making 3 peripheral errors, 4 major rotation errors and 1 major distortion error. In contrast, NL was intact on all the colour Stroop tasks including the baseline conditions (Pardo, Pardo, Janer \& Raichle, 1990). NL's z-score based on slightly older control subjects was 0.54 for the Stroop condition.

Specific subtests of the Boston Diagnostic Aphasia Exam were used to investigate NL's speech and language profile. NL's speech was perceived as stiff and distorted when producing automatized sequences (e.g., counting, reciting the alphabet and nursery rhymes). In addition, she made 3 errors on these tasks, one on days of the week, one on counting to 21 , and one on the alphabet. In the Recitation, Singing and Rhythm subsection, NL was able to recite the words for the nursery rhymes Jack and Jill as well as Baa baa black sheep, but not There was an old woman who lived in a shoe. NL's speech in these recitations was similar to her atypically accented spontaneous and conversational speech. However when asked to sing the same rhymes, NL was fluent and her accent reverted to SSBE. On rhythm tapping repetition tasks NL was impaired on the first two (easier) tasks but intact on the last two (more difficult) tasks. On repeating phrases NL's speech was distorted throughout although she had no difficulty remembering the phrases. In the complex ideational subtest NL scored 12/12, demonstrating intact language comprehension. Likewise, NL scored 20/20 on body part identification. NL made one error on commands, where she tapped each shoulder three times rather than twice on the last item. NL was intact on verbal fluency even on the alternating tasks, which are more difficult.

NL's performance on the Pyramids and Palm Trees Test indicates no impairment at the cognitive level of semantic processing. Finally, NL was asked 
to read aloud a series of questions (both WH-questions and Yes/No questions), which she did fluently, with appropriate intonation and in a recognizable SSBE accent.

As noted, in conversational speech NL had unusual grammatical errors of word order and verb tense in particular. On testing, NL was unable to correctly name two digit numerals such as " 22 " which was named as "two two". However NL correctly read "twenty two" when the numbers were written out.

A SPECT scan performed shortly before our investigation was interpreted as showing an area of decreased perfusion medially in the left fronto-parietal area, with otherwise normal perfusion.

\section{Listener perception of accent}

On first listening, students commented mainly on the good intelligibility, clarity and consistent rhythm of both SUNG and READ speech. RECITED speech was judged unclear, with an uneven rhythm and pauses. REPEAT speech was considered hard to understand, slurred, and unclear. Listeners were virtually unanimous in recognizing a SSBE accent for READ (30/31) and SUNG speech $(24 / 31)^{1}$. For RECITED speech students noted varying accents, primarily French, Spanish or Italian (19/31) but Slavic, Germanic, and African were also proposed. REPEATED speech was mostly perceived as having a French or Spanish accent (13/31), followed by German and Russian. A minority of listeners identified Indian, Middle Eastern and Eastern European accents for REPEATED speech. Overall, undergraduate listeners agree with medical personnel that NL's altered

\footnotetext{
${ }^{1}$ Four listeners sitting together considered SUNG speech to have an Irish English accent, three other listeners noted 'no real accent', a native English accent and an Eastern European accent.
} 
speech has an accent that can be variously labeled in terms of language origin. This variation in response is commonly reported for FAS speech (Coelho \& Robb, 2001; Di Dio et al., 2006; Kurowski et al., 1996).

\section{Impressionistic transcription and voicing variation}

NL sang the nursery rhyme in tune and with a SSBE accent that she and her partner identified as her pre-onset accent. Likewise, NL read four sentences in a self-identified typical, pre-onset accent. In contrast, NL recited the nursery rhyme and repeated two short sentences, in an altered accent. Table 2 presents an agreed phonetic transcription of these four tasks.

Table 2 about here

As a measure of altered consonant production, we calculate Percent Consonants Correct (PCC) and PCC-Revised (Shriberg, Austin, Lewis, McSweeney \& Wilson, 1997). To calculate PCC for RECITED data we assume that consonant production in the SUNG condition corresponds to NL's targets in both versions of the nursery rhyme. We take the number of consonants in the RECITED version that are transcribed as in the SUNG version (i.e. produced without omission, substitution or distortion), divided by the total number of consonants in the SUNG version (the number of target consonants) and multiplied by 100 . This results in a PCC score of 59\% (32/54 x 100). PCC-Revised is a measure of articulation where distortions (in this case longer duration which does not affect identification of place, manner or voice features) are counted as correct. PCC- 
Revised for RECITED data is 69\% (37/54 x 100). NL's PCC for REPEAT data is $62 \%$.

The most common consonantal error in RECITED and REPEAT data is perceived voicing of voiceless targets, which reflects atypical coordination of laryngeal and supralaryngeal activity. Our transcription is supported by spectrographic analysis, see figure 1 of target /k/ and / $/$ in black sheep produced as voiceless [k $\left.\int\right]$ in SUNG, but voiced [ $\mathrm{g} 3$ ] in RECITED.

Figure 1 about here.

In addition, duration of voicing during consonantal closure for postvocalic stops $(n=8)$ is longer in RECITED (.111 sec SD .05 sec) than SUNG (.017 sec SD .006 sec). For the same tokens the percentage of consonantal closure that shows evidence of voicing is also greater in RECITED (62 SD 33) compared with SUNG (32 SD 16). However, a matched samples t-test indicates that the difference between these scores is not significant: $\mathrm{t}(7)=2.83, \mathrm{p}=.025, \mathrm{~d}=1.16$. Other errors in RECITED and REPEAT data include place of articulation ([z] for /ð/), prolonged closure in consonants (note [1:] in figure 1), monotonal intonation, consonant deletion ([h] in /hu/ 'who'; [x] in /Oxi/ 'three', /guin/ and /bıaun/ 'brown'), deaffrication and an intrusive glide [w] in the transition between $[u]$ and $[\varepsilon]$ in [ju wen:i ] 'you any'. NL's SUNG and READ speech preserves dialectally appropriate post-vocalic velarized [ł], whereas her 
RECITED speech uses clear [l] only. This is confirmed by formant analysis, with all tokens of SUNG and READ post-vocalic [1] having a lower F2 than the RECITED counterpart. Finally, reduced pitch variation and altered segmental duration patterns in RECITED and REPEAT data affect the perception of stress. For instance, NL pronounces the word 'colourless' as [kələləz], without unambiguous marking of stress through differences in vowel length, pitch or quality.

Disruption of timing between laryngeal activity and supralaryngeal articulation is reported in FAS speech as long pre-voicing of stops (Blumstein et al., 1987; Kurowski et al., 1996; Haley et al., 2010) and longer consonantal VOTs (Kanjee, Watter, Sévigny \& Humphreys, 2010). Similar to our study, Gurd et al. (1988) and Dankovičová and Hunt (2011) report post-vocalic clear /l/ in the post-onset FAS speech of their subjects. H-dropping is likewise documented in a case of psychogenic FAS (Gurd et al., 2001). NL produces a single manner error (deaffrication), although Moen (2000) and Coelho and Robb (2001) state in their reviews that manner errors are the most common consonantal error in FAS.

In summary, our transcriptions indicate that NL's SUNG and READ speech is consistent with dialectal norms for SSBE, whereas the consonantal alterations in RECITED and REPEAT are departures from typical production that have all been reported in previous cases of FAS.

\section{Acoustic analysis}

Duration 
First we examine the durational qualities of NL's speech at the suprasegmental level (table 3). RECITED and SUNG conditions have identical segmental targets, but it takes NL almost twice as long to recite the nursery rhyme as it does for her to sing it. This is reflected in both total duration and the articulation rate for both tasks.

Table 3 about here

However, a musical score specifies a tempo and the relative duration of the notes to which syllables and words are mapped, so we might ascribe the relatively high articulation rate of NLs SUNG speech to the tempo of the score. However, both typically accented conditions (READ and SUNG) have higher articulation rates than the two atypically accented conditions (RECITED and REPEAT), so the tempo of the tune cannot be the only factor at play. The presence of slower articulation rates in the two atypical conditions (RECITED and REPEAT) is consistent with many cases of FAS, regardless of etiology (Kurowski et al., 1996; Coelho \& Robb, 2001; Katz et al., 2008; Keulen \& Verhoeven et al., 2016).

\section{Word and vowel duration in monosyllables}

For the purposes of word, vowel and consonant duration we examine the monosyllabic words of SUNG $(n=30)$, RECITED $(n=30)$ and READ $(n=29)$ data. Mean word duration (table 3) in RECITED is significantly longer and more variable than word duration in SUNG: $\mathrm{t}(29)=-7.00, \mathrm{p}<.001$. Word duration in READ is shorter again. Not all FAS investigations provide detailed durational 
information, but based on similar methods to ours, the SSBE female speaker in Dankovičová et al. (2001) showed slightly shorter word duration in the FAS condition, though the difference did not reach significance.

Vowels in NL's RECITED speech are longer and more variable (.185 SD .088) than vowels in SUNG (.136 SD .07) and READ conditions (.074 SD .042). However, despite the greater mean duration of vowels in RECITED data, vowel duration as a percentage of word duration is significantly greater in SUNG (48\%) as opposed to RECITED (37\%): $\mathrm{t}(29)=2.9, \mathrm{p}=.006$. This may be an artefact of the singing task. In READ data, vowels are overall $36.4 \%$ of word duration, which is similar to the atypical RECITED data.

Dankovičová et al. (2001) found no significant differences in the duration of pre- and post-onset vowels as a proportion of monosyllabic words. Our findings are not consistent with this in the sense that NL's RECITED vowels in monosyllabic words are significantly shorter than her SUNG vowels as a proportion of word duration. However, the singing task imposes constraints on segment duration that may not accurately reflect NL's unaltered articulation patterns. Compared to her READ vowels, NL's RECITED vowels, while clearly longer, take up the same percentage of overall word duration as her READ vowels. Viewed this way, our findings are in line with Dankovičová et al. (2001). We have noted that both vowel and word duration are greater and more variable in NL's RECITED data relative to both SUNG and READ data. However, the mean and standard deviation on which these differences are calculated does not evaluate the relative duration of adjacent vowels, although syllable-timed and stress-timed languages are known to vary on this dimension (Low et al., 2000). To assess the relative duration of adjacent vowels in NL's speech we use 
the vocalic nPVI (Pairwise Variability Index) equation from Low et al. (2000, p.383). NL's SUNG speech has a nPVI value of 43 while her RECITED speech has a nPVI of 55 (which is near the reference value of 57.2 for British English (Grabe \& Low, 2002)) and her READ speech has a nPVI of 69. If we take READ speech as the reference value because of the temporal distortion dictated by singing, then NL's atypical RECITED speech is relatively more syllable-timed than her unaltered speech. This result is consistent with the tendency towards greater syllable-timing that is reported in FAS, based on lower PVI scores relative to a control or pre-onset speech (Keulen, Mariën et al., 2016; Miller et al., 2006; Roy et al., 2012; Verhoeven \& Mariën, 2010).

\section{Consonant duration in monosyllables}

We turn now to the role of consonant duration in NL's speech. Mean consonant duration is longest in REPEAT and RECITED data, followed by SUNG and READ. Mean consonant duration as a percentage of word duration is significantly greater in the RECITED condition compared to the SUNG condition: $\mathrm{t}(28)=-2.89, \mathrm{p}=.007$. However, comparison of RECITED speech with READ speech shows that the relative duration of consonants and vowels within the word is virtually identical. In other words, NL's RECITED speech is overall slower, but retains the same relative duration of consonants and vowels that are found in her READ speech. NLs REPEAT speech is markedly skewed towards longer consonant duration relative to vowels.

Similar to our data, Verhoeven and Mariën, (2010) report longer consonant duration in the post-onset speech of their client, along with longer vowel duration. Dankovičová, et al. (2001) report both longer consonant 
duration in the accented speech of their participant and a significantly higher percentage of consonant duration as a proportion of word duration.

\section{Vowel quality}

Figure 2 plots normalized values for NL's vowels from all four conditions. For clarity we present two plots, each with a typical and an atypical condition. Vowel quality is labeled using lexical set names from Wells (1982). Unstressed vowels in disyllabic words are excluded and the data are normalized as noted in the methods section. In the top plot, filled circles represent SUNG vowels, with solid lines connecting the most peripheral vowels from that condition. Unfilled circles represent RECITED vowels, with dotted lines connecting the peripheral vowels from that condition. In the bottom plot, filled diamonds connected by solid lines represent READ vowels, and unfilled diamonds connected by dotted lines are from the REPEAT condition. The resulting quadrilaterals encompass the extremes of NL's SUNG, RECITED, READ and REPEAT vowel space. The centroid or S-point for NL's vowels is defined as $(1,1)$ on the graph. Figure 2 also includes reference vowels (asterisks) for /i, a, $\mathrm{u}$ / as produced by five female speakers of Standard Southern British English (Deterding, 1997).

Figure 2 about here 
Overall, the space occupied by RECITED vowels in monosyllables is larger than SUNG vowels in the F1 (tongue height) dimension, but a comparison of mean F1 values for all RECITED and SUNG vowels revealed no statistically significant difference: $t(26)=1.13 ; p=.265$. The top plot shows GOOSE-fronting, but not FOOT-fronting in the SUNG data, which is consistent with a SSBE speaker of NL's age at the time of recording, whereas the RECITED data has an unusual reverse pattern with FOOT-fronting but no GOOSE-fronting (Bjelaković, 2016; Ferragne \& Pellegrino, 2010).

Compared to published norms for formant values of SSBE, NL's RECITED GO0SE vowel is articulated further back than expected, but the F1 values for FLEECE and GOOSE are not unusual for female speakers (Deterding 1997). While NL's RECITED vowel space does show greater tongue raising and lowering than her SUNG vowel space, NL's RECITED vowel space is largely within norms for her age, gender and dialect at the time of recording. NL's READ vowels are intermediate between the SUNG and RECITED data, and likewise within published norms. NL's REPEAT vowels are based on limited data, with the FLEECE vowel as expected. The TRAP and GOOSE corner vowels are not represented in the REPEAT data.

Vowel quality in FAS data can be more peripheral (Graff-Radford et al., 1986; Blumstein et al., 1987) or more reduced (Coelho \& Robb, 2001; Lewis et al., 2012). The figures in Lewis et al. (2012) show extensive backing of front vowels and lesser fronting of back vowels, which introduces the possibility of some vowel dimensions being more affected than others. Roy et al. (2012) describe a FAS speaker with primarily restricted F1 range, whereas Dankovičová 
et al. (2001) report a significant difference in F2 in pre and post onset data, but not F1.

Clearly, vowel quality changes in FAS data can vary in terms of which formant is most affected, and in some cases whether front or back vowels are most altered. NL's RECITED data shows an expanded F1 range only relative to her SUNG vowels and we have established that even her atypical RECITED and REPEAT vowels are largely within community norms of the last 50 years. Nonetheless, Weber fractions (table 4) using SUNG vowels as the reference value indicate that all F1 and F2 differences between SUNG and RECITED vowels are larger than the .03 threshold for perception of difference fifty percent of the time, with a single exception (F1 in the DRESS vowel). Therefore, the differences between NL's RECITED and SUNG vowels are large enough to be perceived (Rosner \& Pickering, 1994).

Table 4 about here.

\section{Fundamental frequency}

NL sings a common version of the nursery rhyme in which the maximum frequency range is one octave. NL's fundamental frequency, based on averages of each word in the tune, ranges from 131 to $278 \mathrm{~Hz}$, with a span of $147 \mathrm{~Hz}$ (table 5). NL's SUNG range is slightly more than the octave that the tune requires.

Table 5 about here. 
Compared to this, NL's RECITED speech has a frequency span of $34 \mathrm{~Hz}$ (135 -169

$\mathrm{Hz}$ ). There is a significant difference in average F0 per word for RECITED

$(\mathrm{M}=150.6 \mathrm{~Hz}, \mathrm{SD}=8.34 \mathrm{~Hz})$ and $\mathrm{SUNG}(\mathrm{M}=184.05, \mathrm{SD}=36.29 \mathrm{~Hz})$ conditions: $\mathrm{t}(32)$

$-5.04, \mathrm{p}<.001$. The difference between the two conditions is clear in figure 3

(top), which compares the F0 trace from the first line of the nursery rhyme in SUNG and RECITED conditions.

Figure 3 about here

Since a singing task is expected to elicit the F0 range that the tune demands, we can better compare NL's RECITED data to an F0 range for typical speakers of English, and to her own READ speech (figure 3, bottom right). A typical F0 range for spoken English is roughly an octave (Laver 1994; Grabe \& Coleman, (2006); Andreeva, Demenko, Wolska, Möbius, Zimmerer, Jugler, ...Trouvain, 2014). NL's READ speech exceeds this one octave range while her RECITED and REPEAT speech both have a much reduced F0 range. Overall, in the RECITED and REPEAT tasks NL shows limited control of F0 in terms of frequency of vocal fold vibration (reduced range) and timing with supralaryngeal events. On the other hand, NL's SUNG and READ data shows that she is physiologically capable of a typical one octave speaking range, precise control of F0 and dialectally appropriate timing of voice contrasts.

The reduced pitch range of NL's accented speech is attested in other cases of FAS (Graff-Radford et al., 1988; Kuschmann, Lowit, Miller \& Mennen, 2012). 
NL's lower mean F0 for RECITED and REPEAT data relative to SUNG and READ data is paralleled in Verhoeven and Mariën's data (2010) although the reverse is found in Blumstein et al. (1987), Coelho and Robb (2001), Lewis et al. (2012), Miller et al. (2006), Ryalls and Whiteside (2006). Dankovičová et al. (2001) found no significant difference in mean F0 values of their volunteer's pre- and post-onset speech, based on lexical and phrasal pitch prominence.

\section{Pyschogenic etiology}

Keulen and Verhoeven et al. (2016, p. 12-13) propose a constellation of features which tend to occur in clients with psychogenic FAS, including psychological and/or psychiatric indicators; being female; being within the age range of 25-49 years old; having both segmental and suprasegmental changes in their speech including variable pitch, speech and articulation rates; pseudoagrammaticisms that are not typical of aphasia, and the possibility of dramatic remission. NL's assessment revealed clinical levels of anxiety, little evidence of organic change and odd grammatical and morphological errors that do not fit established profiles of known language disorders. Our participant was lost to follow up so we have no knowledge of remission. Along with these features, phonetic examination of NL's accented speech includes all of the features that Keulen et al. (2016) note in psychogenic FAS. However, none of these phonetic features are exclusive to non-organic or psychogenic FAS .

\section{SUMMARY AND DISCUSSION}


NL presents an unusual combination of typically accented singing and reading, contrasting with atypically accented spontaneous speech, repetition and recitation. It is not uncommon for singing and other rhythmic tasks to be relatively unaffected in cases of neurological damage which affect speech production, but NLs combination is striking, and not attested in the literature on FAS. A potential parallel is the Laures-Gore et al. (2006) study of (possibly psychogenic) FAS in which an African American woman spoke with a Jamaican or Spanish accent which disappeared when she sang. However, some of the nonsinging speech tasks used in assessing this patient were read from cue cards, and produced in an atypical accent. As a result, this client's pattern does not match the overall profile of NL, who has her typical accent in reading tasks.

We note that NL is left handed, and may therefore be atypically crosslateralized or bi-lateralized for (some) language function(s). It is accepted that right hemisphere pathways may be active in singing tasks, but particularly in the presence of L-handedness. It is interesting in NL's case that these pathways would be activated in singing but not in recitation of well-known nursery rhymes. In addition, Stahl, Kotz, Henseler, Turner \& Geyer (2011) argue that it is rhythm, not singing per se, that supports the speech improvements noticed by some people with non-fluent aphasia when singing. As a result they predict that recitation of known material should likewise enable improved speech, which is documented in the sense that some people with aphasia recite familiar prayers and poems in fluent speech. Again, this pattern is distinct from NL's, who recites the nursery rhyme in accented speech. We might look to NL's test results in recitation, singing and rhythm for clarification, yet here NL was impaired on easier rhythm tapping repetition tasks, but unimpaired on the more difficult 
tasks. It is unclear therefore, whether NL's production of rhythm per se is compromised or not, and therefore it is unclear whether or not the rhythmicity of singing the nursery rhyme contributes to her ability to produce unaccented sung speech.

NL did present with buccofacial apraxia in non-speech tasks from the Boston Diagnostic Aphasia Exam (Goodglass, 1983), with mixed additional language assessment results indicative of aphasia-like elements, but in very unexpected combinations. Given the highly unusual, contradictory mix of speech and language features with which NL presented, the lack of supporting evidence for organic injury and unavoidable limits on data design, we suggest that full discussion of causality and/or differential diagnosis is beyond the scope of this case report. Overall, there is little about the available evidence which amounts to a clear-cut picture, particularly given the contradiction between intact Stroop task performance (sensitive to frontal lobe supplementary motor area dysfunction), and the uneven fronto-temporal profile on other cognitive tasks. Further speech data, while desirable, cannot mitigate these facts. As it stands, we consider NL's case one that emphasizes the relevance and utility of diagnostically 'agnostic' linguistic, neuropsychological descriptions and analyses of behaviour patterns with respect to specific speech alterations and cognitive profiles. As experimentalists, we contribute this case description in the context of its: (a.) referral by a clinical neurologist/psychiatrist as 'psychogenic' in origin; and (b.) a neuropsychology profile sufficiently inconsistent and markedly unusual as to further support that clinical descriptor.

Acknowledgements: We are grateful to NL for her patience and cooperation. 
Declaration of interest: Research was supported by The John Fell Fund (UK), the Medical Research Council (UK), and the Critchley Charitable Trust (UK) 


\section{References}

Andreeva, B., Demenko, G., Wolska, M., Möbius, B., Zimmerer, F., Jugler, J., . . . Trouvain, J. (2014). Comparison of pitch range and pitch variation in Slavic and Germanic languages. In N. Campbell, D. Gibbon, \& D. Hirst (Eds.), Speech prosody 7: Proceedings of the 7th International Conference on Speech Prosody. Dublin.

Aronson, A. (1980). Clinical voice disorders: An interdisciplinary approach. New York: Theime Publishers.

Bakker, J. I., Apeldoorn, S., \& Metz, L. M. (2004). Foreign accent syndrome in a patient with multiple sclerosis. Canadian Journal of Neurological Science, 31(2), 271-272.

Berthier, M., Ruiz, A., Massone, M., Starkstein, S., \& Leiguarda, R. (1991). Foreign accent syndrome: Behavioral and anatomical findings in recovered and non-recovered patients. Aphasiology, 5, 129-147.

Bjelaković, A. (2016). The vowels of contemporary RP: vowel formant measurements for BBC newsreaders. English Language and Linguistics. doi:10.1017/S1360674316000253

Blumstein, S. E., Alexander, M. P., Ryalls, J. H., Katz, W., \& Dworetzky, B. (1987). On the nature of the foreign accent syndrome: a case study. Brain and 
Language, 31(2), 215-244.

Blumstein, S. E., \& Kurowski, K. (2006). The foreign accent syndrome: A perspective. Journal of Neurolinguistics, 19(5), 346-355.

Boersma, P. \& Weenink, D. (2014). Praat: Doing phonetics by computer (Version 5.3.84) [Computer program]. Retrieved from http://www.praat.org/

Chanson, J. B., Kremer, S., Blanc, F., Marescaux, C., Namer, I. J., \& de Seze, J. (2009). Foreign accent syndrome as a first sign of multiple sclerosis. Multiple Sclerosis, 15(9), 1123-1125.

Coelho, C., \& Robb, M. P. (2001). Acoustic analysis of foreign accent syndrome: An examinimation of three explantory hypotheses. Journal of Medical Speech-Language Pathology, 9(4), 227-242.

Corsi, P. (1972). Human memory and the medial temporal region of the brain.

(Doctoral Thesis). Retrieved from http://digitool.Library.McGill.CA:80/R/-

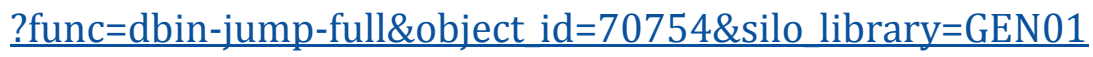

Dankovičová, J., Gurd, J. M., Marshall, J.C., MacMahon, M.K.C., Stuart-Smith, J., Coleman, J.S. \& Slater, A. (2001). Aspects of non-native pronunciation in a case of altered accent following stroke (foreign accent syndrome). Clinical Linguistics and Phonetics, 15 (3), 195-218. 
Dankovičová, J., \& Hunt, C. (2011). Perception of foreign accent syndrome speech and its relation to segmental characteristics. Clinical Linguistics and Phonetics, 25(2), 85-120.

Deterding, D. H. (1997). The formants of monophthong vowels in Standard Southern British English pronunciation. Journal of the International Phonetic Association, 27, 47-55.

Di Dio, C., Schultz, J., \& Gurd, J. M. (2006). Foreign Accent Syndrome: in the ear of the beholder? Aphasiology, 20, 951-962.

Ferragne, E., \& Pellegrino, F. (2010). Formant frequencies of vowels in thirteen accents of the British Isles. Journal of the International Phonetic Association, 40(1), 1-34.

Goodglass, H. (1983). The assessment of aphasia and related disorders. The Boston diagnostic aphasia examination. Philadelphia: Lea \& Febiger.

Grabe, E. \& Coleman, J. (2006). Intonational variation in English: Fact sheet. Available at www.phon.ox.ac.uk/files/apps/IViE/leaflet.pdf

Grabe, E., \& Low, E. L. (2002). Acoustic correlates of rhythm class. In C. Gussenhoven \& N. Warner (Eds.), Papers in Laboratory Phonology 7 (pp. 515-546). Berlin: De Gruyter Mouton. 
Graff-Radford, N., Cooper, W., Colsher, P., \& Damasio, A. (1986). An unlearned foreign 'accent' in a patient with aphasia. Brain and Language, 28, 86-94.

Gurd, J., Bessell, N., Bladon, A. \& Bamford, J. (1988). A case of Foreign Accent Syndrome with follow-up clinical, neuropsychological and phonetic descriptions. Neuropsychologia 26, 237-251.

Gurd, J. \& Coleman, J. (2006). Foreign accent syndrome: Best practice, theoretical issues and outstanding questions. Journal of Neurolinguistics 19, 424-429.

Gurd, J., Coleman, J., Costello, A., \& Marshall, J. (2001). Organic or functional? A new case of foreign accent syndrome. Cortex, 37, 715-8.

Haley, K. L., Roth, H. L., Helm-Estabrooks, N., \& Thiessen, A. (2010). Foreign accent syndrome due to conversion disorder: Phonetic analyses and clinical course. Journal of Neurolinguistics, 23(1), 28-43.

Hieronymous, M., Alexander, E., Bennett, C. C., Cohen, I., Davies, D., Dalby, J., . . . Wells, J. (1990). Speech segmentation criteria for the SCRIBE project. The SCRIBE Project Report.

Howard, D. \& Patterson, K. (1992). Pyramids and palm trees: A test of semantic access using pictures and words. Bury St. Edmunds: Thames Valley Test Company. 
Ingram, J., McCormack, P., \& Kennedy, M. (1992). Phonetic analysis of a case of foreign accent syndrome. Journal of Phonetics 20, 457-474.

Jonkers, R., van der Scheer, F., \& Gilbers, D. (2016). The common denominator in the perception of accents in cases with foreign accent syndrome. Aphasiology, doi:10.1080/02687038.2016.1232362

Kanjee, R., Watter, S., Sévigny, A., \& Humphreys, K. R. (2010). A case of foreign accent syndrome: Acoustic analyses and an empirical test of accent perception. Journal of Neurolinguistics, 23(6), 580-598.

Katz, W. F., Garst, D. M., \& Levitt, J. (2008). The role of prosody in a case of foreign accent syndrome (FAS). Clinical Linguistics and Phonetics, 22(7), 537-566.

Keulen, S., Mariën, P., Wackenier, P., Jonkers, R., Bastiaanse, R., \& Verhoeven, J. (2016). Developmental Foreign Accent Syndrome: Report of a new case. Front Hum Neurosci, 10, 65.

Keulen, S., Verhoeven, J., De Witte, E., De Page, L., Bastiaanse, R., \& Mariën, P. (2016). Foreign Accent Syndrome as a psychogenic disorder: A review. Frontiers in Human Neuroscience, 10, 168. doi:10.3389/fnhum.2016.00168

Kurowski,K., Blumstein, S. \& Alexander, M. (1996). The FAS: A reconsideration. 
Brain and Language, 54, 1-15.

Kuschmann, A., Lowit, A., Miller, N., \& Mennen, I. (2012). Intonation in neurogenic foreign accent syndrome. Journal of Communication Disorders, 45(1), 1-11.

Laures-Gore, J., Henson, J. C., Weismer, G., \& Rambow, M. (2006). Two cases of foreign accent syndrome: an acoustic-phonetic description. Clinical Linguistics and Phonetics, 20(10), 781-790.

Laver, J. (1994). Principles of phonetics. Cambridge: Cambridge University Press.

Lewis, S., Ball, L., \& Kitten, S. (2012). Acoustic and perceptual correlates of foreign accent syndome with manic etiology: A case study. Communication Disorders Quarterly, 34(4), 242-247.

Lippert-Gruener, M., Weinert, U., Greisbach, T., \& Wedekind, C. (2005). Foreign accent syndrome following traumatic brain injury. Brain Injury, 19(11), 955-958.

Low, E., Grabe, E., \& Nolan, F. (2000). Quantitative characterisation of speech rhythm: Syllable timing in Singapore English. Language and Speech, 43, $377-401$.

Miller, N. (2007).The merry vibes of wintzer: The tale of foreign accent 
syndrome. In Della Sala, S. (Ed.), Tall tales about the mind and the brain. Oxford: Oxford University Press.

Miller, N., Lowit, A., \& O’Sullivan, H. (2006). What makes acquired foreign accent syndrome foreign? Journal of Neurolinguistics, 19(5), 385-409.

Moen, I. (2000) Foreign accent syndrome: A review of contemporary explanations. Aphasiology, 14(1), 5-15.

Monrad-Krohn, G. (1947). Dysprosody or altered "melody of language”. Brain, 70, 405-415.

Moonis, M., Swearer, J., Blumstein, S. E., Kurowski, K., Licho, R., Kramer, P., . . . Drachman, D. (1996). Foreign accent syndrome following a closed head injury: Perfusion deficit on single photon emission tomography with normal magnetic resonance imaging. Neuropsychiatry, Neuropsychology and Behavioural Neurology, 9, 272-279.

Pardo, J.V., Pardo, P.J., Janer, K.W., Raichle, M.E. (1990) The anterior cingulate cortex mediates processing selection in the Stroop attentional conflict paradigm. Proceedings of the National Academy of Sciences, USA, 87, 256259.

Perkins, R. \& Ryalls, J. (2013). Vowels in foreign accent syndrome. In M. Ball \& F. Gibbon (Eds.), Handbook of vowels and vowel disorders (pp. 347-363). UK: 
Psychology Press.

Perkins, R., Ryalls, J., Carson, C., \& Whiteside, J. (2010). Acoustic anlyses of two recovered cases of foreign accent syndrome. Aphasiology, 24, 1132-1154.

Reeves, R., Burke, R. and Parker, J. (2007). Characteristics of psychotic patients with foreign accent syndrome. Journal of Neuropsychiatry and Clinical Neuroscience 19, 70-76.

Rey, A. (1941). L'examen psychologique dans le cas d'encephalopathie traumatique. Archives de Psychologie, 28, 215-285.

Rosner, B. \& Pickering, J. (1994). Vowel perception and production. Oxford: OUP.

Roy, J. P., Macoir, J., Martel-Sauvageau, V., \& Boudreault, C. A. (2012). Two French-speaking cases of foreign accent syndrome: an acoustic-phonetic analysis. Clinical Linguistics and Phonetics, 26(11-12), 934-945.

Ryalls, J., \& Miller N. (2014) Foreign accent syndromes: the stories people have to tell. Sussex: Psychology Press.

Ryalls, J., \& Whiteside, J. (2006). An atypical case of Foreign Accent Syndrome. Clinical Linguistics and Phonetics, 20(2-3), 157-162.

Scarpini, F., \& Tagini, S. (2017). The Stroop Colour and Word Test. Frontiers in Psychology 8, 557. http://doi.org/10.3389/fpsyg.2017.00557 
Shriberg, L. D., Austin, D., Lewis, B. A., McSweeny, J. L., \& Wilson, D. L. (1997). The Percentage of Consonants Correct (PCC) metric: Extensions and reliability data. Journal of Speech Language and Hearing Research, 40(4), 708-722.

Sivan, A. B. (1992). Benton Visual Retention Test (5th ed.). San Antonio: The Psychological Corporation.

Stahl, B., Kotz, S. A., Henseler, I., Turner, R., \& Geyer, S. (2011). Rhythm in disguise: why singing may not hold the key to recovery from aphasia. Brain, 134(10), 3083-3093. doi:10.1093/brain/awr240

Stroop, J. R. (1935). Studies of interference in serial verbal reactions. Journal of Experimental Psychology, 18, 643-662.

Thomas, E., \& Kendall, T. (2007). NORM: The vowel normalization and plotting suite.

Varley, R., Whiteside, S., Hammill, C., \& Cooper, K. (2006). Phases in speech encoding and foreign accent syndrome. Journal of Neurolinguistics, 19(5), 356-369.

Verhoeven, J., \& Mariën, P. (2010). Neurogenic foreign accent syndrome: Articulatory setting, segments and prosody in a Dutch speaker. Journal of 
Neurolinguistics, 23(6), 599-614.

Watt, D., \& Fabricius, A. (2002). Evaluation of a technique for improving the mapping of multiple speakers' vowel spaces in the F1-F2 plane. . Leeds Working Papers in Linguistics and Phonetics, 9, 159-173.

Wechsler, D. (1987). Wechsler memory scale-revised WMS-R. San Antonio: The Psychological Corporation.

Wells, J. (1982). Accents of English. Cambridge: CUP.

Whitaker, H. A. (1982). Levels of impairment in disorders of speech. In R. N. Malatesha \& L. C. Hartlage (Eds.), Neuropsychology and Cognition vol. 1 (pp. 168-207). The Hague: Nijhoff.

Yamadori, A., Osumi, Y., Masahura, S., \& Okubo, M. (1977). Preservation of singing in Broca's aphasia. Journal of Neurology, Neurosurgery and Psychiatry, 40, 221-224.

Zigmond, A.S. \& Snaith, R.P. (1983). The hospital anxiety and depression scale. Acta Psychiatrica Scandinavica, 67, 361-370. 
Table 1: Summary of Cognitive Assessment and BDAE Results

Table 2: IPA Transcriptions

Table 3: Durations and Ratios

Table 4: Weber fractions for F1 and F2 Monophthongs SUNG and RECITED

Table 5: F0 (Hz) in Each Task 
Table 1

Summary of Cognitive Assessment and BDAE Results

Test

Subtest

Score

Interpretation

Hospital Anxiety and Depression scale

Anxiety

12,8

impaired

Depression

1,3

unimpaired

Rey Figure copy

Immediate recall

$31 / 36$

impaired

Delayed recall

impaired

Benton Visual Retention Task

8

see below

Wechsler Memory Scale

Logical Memory (Paragraph Recall)

Immediate

9

Delayed

9

Forward digit span

7

Backwards digit span

4

Corsi Block Test

5

unimpaired unimpaired unimpaired see below

unimpaired

Stroop Color and Word Test

unimpaired

Boston Diagnostic Aphasia Examination

Oral expression

Non-verbal agility $\quad 2 / 12$

Verbal agility $\quad 8 / 12$

impaired

impaired

Word comprehension_

Body parts 20/20

Commands $\quad 9 / 10$

Complex ideational material $\quad 12 / 12$

Automatised sequences

Recitation, melody, rhythm

$4 / 8$

Repetition

Boston Naming Test

$100 \%$

Pyramids and Palm Trees Test unimpaired unimpaired unimpaired see below see below see below unimpaired

unimpaired 
Table 2

IPA Transcription

\begin{tabular}{|c|c|c|}
\hline Text & RECITED & SUNG \\
\hline \multirow{2}{*}{$\begin{array}{l}\text { 1. Baa baa black sheep } \\
\text { have you any wool? }\end{array}$} & ba ba b:l:ag zip fav ju & ba ba blak Jip hav ju $\varepsilon n i$ \\
\hline & wعn:i wə̆l (breath .546s) & wŭł (breath .360s) \\
\hline \multirow{2}{*}{$\begin{array}{l}\text { 2. Yes sir yes sir three } \\
\text { bags full. }\end{array}$} & jez(s)3 jez(s)3 zi bagz & jes3 jes3 ðıi bagz fł̣ \\
\hline & făl (breath .535s) & (breath .40s) \\
\hline \multirow{2}{*}{$\begin{array}{l}\text { 3. One for the master one } \\
\text { for the dame. }\end{array}$} & wn: və zə 'mazdə wn və & wn fə ðə 'mast ${ }^{\mathrm{h}} \partial$ wn fว \\
\hline & zə deIm (breath .426s) & ðə deIm (breath .356s) \\
\hline \multirow{3}{*}{$\begin{array}{l}\text { 4. One for the little boy } \\
\text { who lives down the lane. }\end{array}$} & wn vว zə 'l:Itว̆l buı u & wn fว ठə lit $t^{\mathrm{h}} \underset{\text { bo }}{\text { bo }}$ hu \\
\hline & livz d:aun (breath .462s) & livz daun ðə leın \\
\hline & zə l:eIn & \\
\hline
\end{tabular}

\begin{tabular}{lll}
\hline Text & REPEAT & Notes \\
\hline $\begin{array}{l}\text { 1. Colourless green ideas } \\
\text { sleep furiously. }\end{array}$ & kəl:əl:əz gi:n aıdıəz:l:i:b & Monotone pitch; equal \\
& $\mathrm{f}^{\mathrm{w}}$ uIəzli: & $\begin{array}{l}\text { stress creates syllable- } \\
\text { timed rhythm; full }\end{array}$ \\
$\begin{array}{l}\text { 2. The quick brown fox } \\
\text { jumped over the foggy } \\
\text { heath. }\end{array}$ & ze kwIk baun vDgz & voicing of lenis \\
& $3 \Lambda \mathrm{mp}\urcorner \mathrm{t}$ ouvə zi vpgi fiz & consonants
\end{tabular}

\begin{tabular}{|c|c|c|}
\hline Text & READ & Notes \\
\hline $\begin{array}{l}\text { 1. What's the first board } \\
\text { game you can think of? }\end{array}$ & 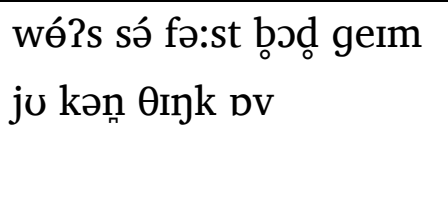 & $\begin{array}{l}\text { Dynamic intonation } \\
\text { contours with typical } \\
\text { variation (acute accent }\end{array}$ \\
\hline $\begin{array}{l}\text { 2. What is the last film } \\
\text { you saw? }\end{array}$ & 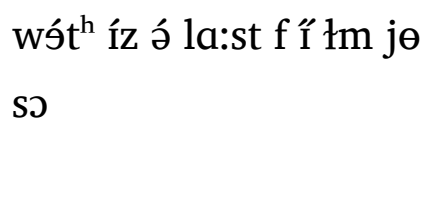 & $\begin{array}{l}\text { marks higher pitches); } \\
\text { appropriate devoicing } \\
\text { of lenis consonants; }\end{array}$ \\
\hline $\begin{array}{l}\text { 3. What is your favourite } \\
\text { day of the week? }\end{array}$ & $\begin{array}{l}\text { wót }{ }^{\mathrm{h}} \text { Íz jó fe:IVıI? deI əv } \\
\text { ðə wik }{ }^{\mathrm{h}}\end{array}$ & $\begin{array}{l}\text { more rapid, stress-timed } \\
\text { rhythm than REPEAT }\end{array}$ \\
\hline $\begin{array}{l}\text { 4. What is your favourite } \\
\text { sport to watch on TV? }\end{array}$ & $\begin{array}{l}\text { wət }{ }^{\mathrm{h}} \text { Íz jő fe:Ivıə? spə:? } \\
\mathrm{t}^{\mathrm{h}} \boldsymbol{\theta} \text { wdt } \int \mathrm{pn} \mathrm{t}^{\mathrm{h}} \mathrm{i} \text { vî: }\end{array}$ & sentences. \\
\hline
\end{tabular}


Table 3

Durations and Ratios

\begin{tabular}{|c|c|c|c|c|c|c|}
\hline & REPEAT & READ & RECITED S & SUNG & $\begin{array}{l}\text { Ratio } \\
\text { RECITED: } \\
\text { SUNG }\end{array}$ & $\begin{array}{l}\text { Ratio } \\
\text { RECITED } \\
\text { READ }\end{array}$ \\
\hline Duration (s) & 12.38 & 7.54 & 19.54 & 10.64 & 1.84 & \\
\hline $\begin{array}{l}\text { No. of } \\
\text { syllables }\end{array}$ & 22 & 35 & 36 & 36 & 1 & \\
\hline $\begin{array}{l}\text { Articulation } \\
\text { rate }\end{array}$ & 1.78 & 4.68 & 2.05 & 3.77 & .54 & \\
\hline $\begin{array}{l}\text { Mean word } \\
\text { duration (s) }\end{array}$ & $\begin{array}{r}.756 \\
\text { SD .396 }\end{array}$ & $\begin{array}{r}.203 \\
\text { SD .118 }\end{array}$ & $\begin{array}{r}.498 \\
\text { SD .207 }\end{array}$ & $\begin{array}{r}.28 \\
\text { SD .13 }\end{array}$ & 1.78 & \\
\hline $\begin{array}{l}\text { Mean vowel } \\
\text { duration (s) }\end{array}$ & $\begin{array}{r}.167 \\
\text { SD .048 }\end{array}$ & $\begin{array}{r}.074 \\
\text { SD .042 }\end{array}$ & $\begin{array}{r}.185 \\
\text { SD .088 }\end{array}$ & $\begin{array}{r}.136 \\
\text { SD .07 }\end{array}$ & 1.37 & \\
\hline $\begin{array}{l}\mathrm{V} / \mathrm{W} \\
\text { (percent) }\end{array}$ & 22 & 35 & 37 & 49 & .76 & \\
\hline $\begin{array}{l}\text { Mean } \\
\text { consonant } \\
\text { duration }(s)\end{array}$ & $\begin{array}{r}.588 \\
\text { SD .382 }\end{array}$ & $\begin{array}{r}.137 \\
\text { SD .103 }\end{array}$ & $\begin{array}{r}.323 \\
\text { SD .211 }\end{array}$ & $\begin{array}{r}.148 \\
\text { SD .09 }\end{array}$ & 2.18 & \\
\hline $\begin{array}{l}\mathrm{C} / \mathrm{W} \\
\text { (percent) }\end{array}$ & 77 & 67 & 65 & 53 & 1.22 & \\
\hline PVI & & 69 & 55 & 43 & & \\
\hline \multicolumn{7}{|c|}{$\begin{array}{l}\text { Note: Word duration, } V \text { duration, } \mathrm{C} \text { duration and Pairwise Variability Index (PVI) } \\
\text { measured on monosyllabic words only ( } \mathrm{n}=30 \text { for SUNG, RECITED; } \mathrm{n}=29 \text { for } \\
\text { READ; } \mathrm{n}=9 \text { for REPEAT). Insufficient data to calculate PVI on REPEAT data. }\end{array}$} \\
\hline Vowel & F1 & F2 & Vowel & F1 & & 82 \\
\hline FLEECE & .177 & .052 & NORTH & .04 & & 055 \\
\hline KIT & .169 & .21 & FOOT & .18 & & 403 \\
\hline DRESS & .011 & .062 & GOOSE & .27 & & 331 \\
\hline TRAP & .238 & .035 & NURSE & .05 & & 342 \\
\hline BATH & .171 & .12 & COMMA & .18 & & 137 \\
\hline STRUT & .034 & .074 & & & & \\
\hline
\end{tabular}


Table 5

FO (Hz) in Each Task

\begin{tabular}{llll}
\hline Task & Range & Mean & SD \\
\hline REPEAT & $151-175$ & 161 & 7.5 \\
READ & $131-327$ & 196 & 70 \\
RECITED & $135-169$ & 151 & 8 \\
SUNG & $131-278$ & 184 & 36 \\
\hline
\end{tabular}


Figure 1. Waveform and spectrogram of SUNG (top): 'black sheep' [blak Jip], duration of section $=.704$ seconds. Waveform and spectrogram of RECITED (bottom): 'black sheep' [b:1:ag 3ip], duration of section $=1.066$ seconds

Figure 2. Vowel formant plot, normalised. SUNG (solid circles, solid lines); RECITED (unfilled circles, dotted lines); READ (solid diamond, solid lines); REPEAT (unfilled diamond, dotted lines); reference vowels for SSBE (asterisk) based on Deterding (1977)

Figure 3. F0 (Hz) traces of RECITED (top left), SUNG (top right), REPEAT (bottom left) and READ (bottom right) speech 

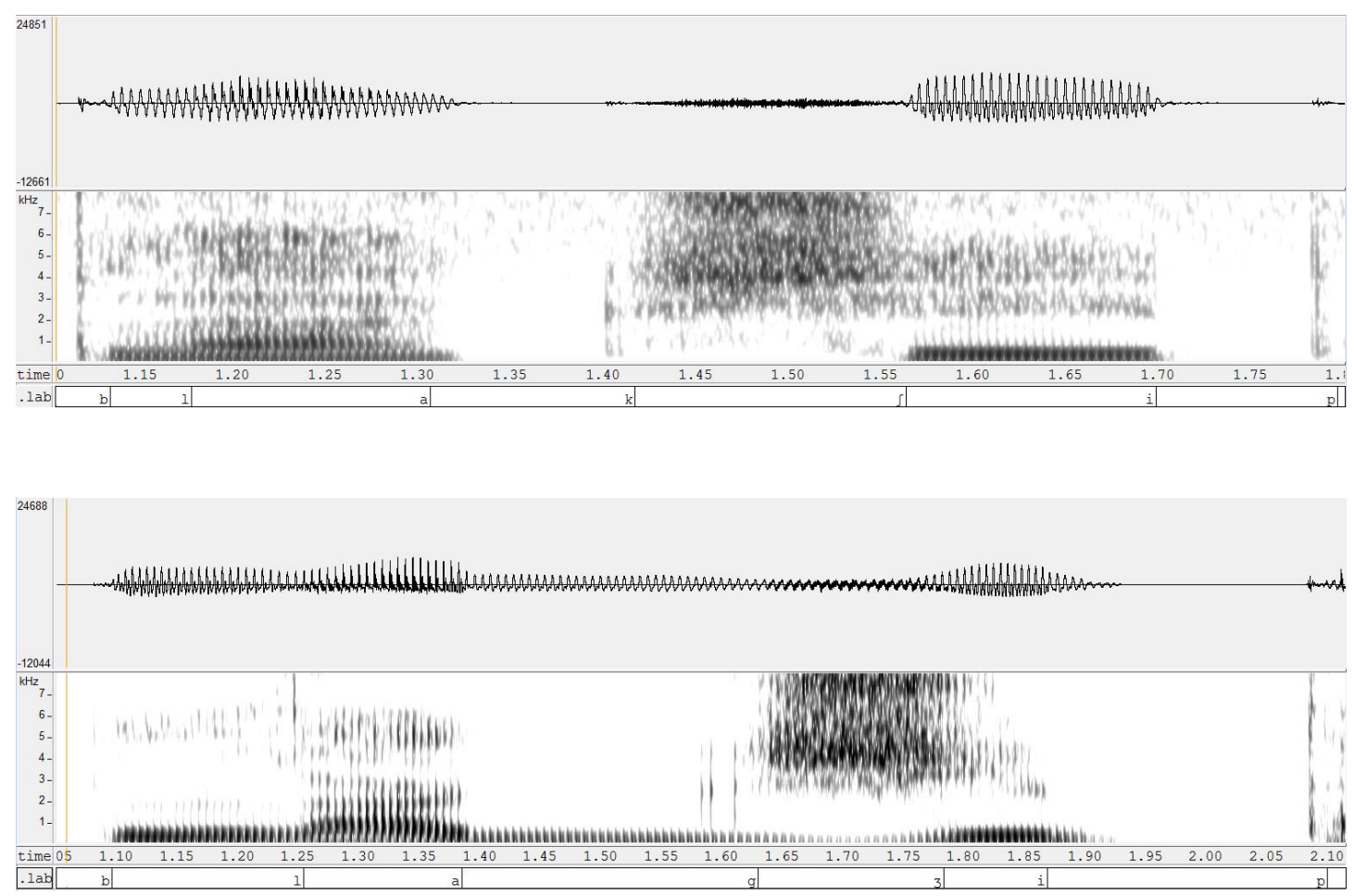

Figure 1. Waveform and spectrogram of SUNG (top): 'black sheep' [blak Jip], duration of section $=.704$ seconds. Waveform and spectrogram of RECITED (bottom): 'black sheep' [b:1:ag 3ip], duration of section $=1.066$ seconds 

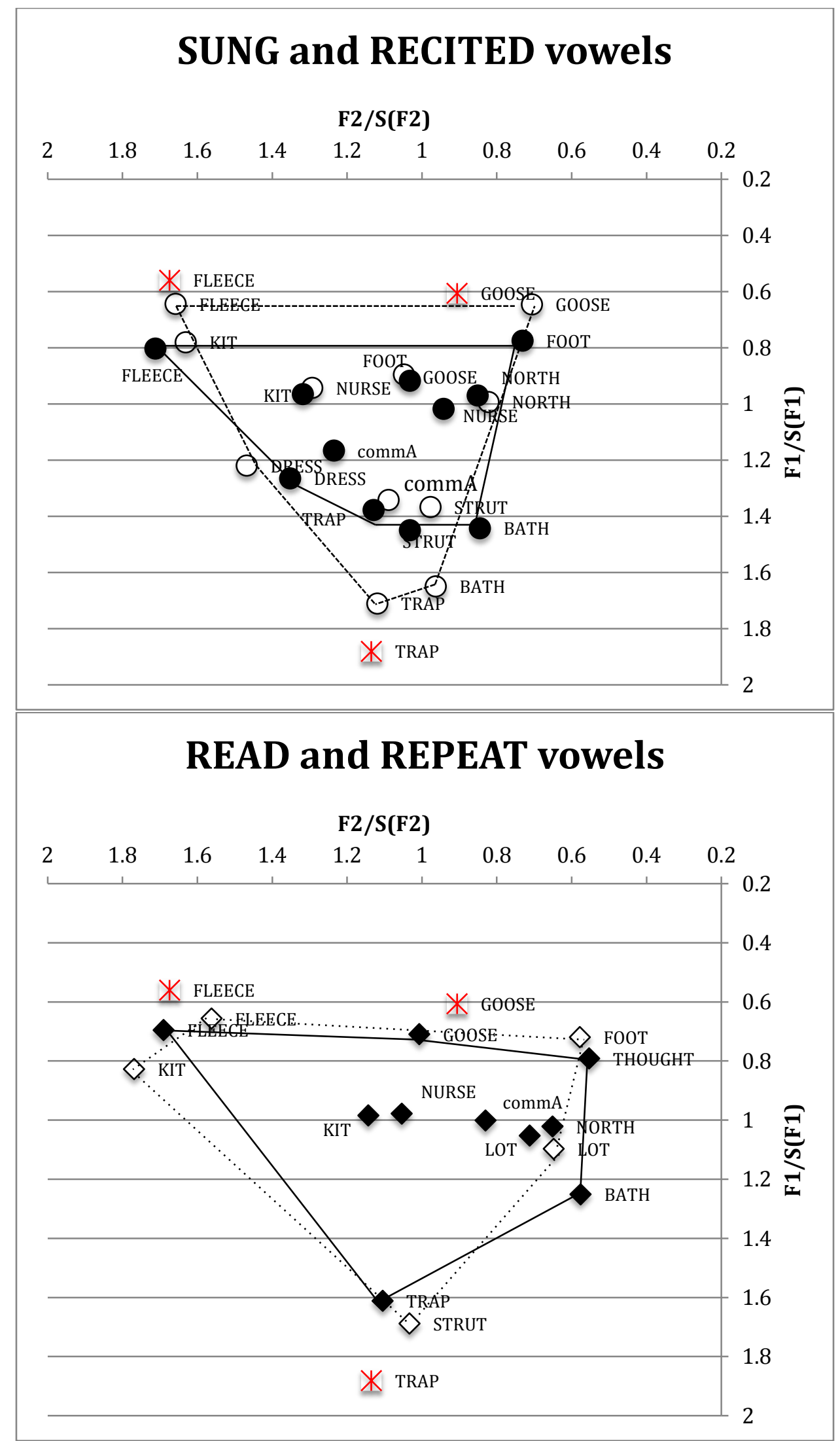

Figure 2. Vowel formant plot, normalised. SUNG (solid circles, solid lines); RECITED (unfilled circles, dotted lines); READ (solid diamond, solid lines); REPEAT (unfilled diamond, dotted lines); reference vowels for SSBE (asterisk) based on Deterding (1977) 

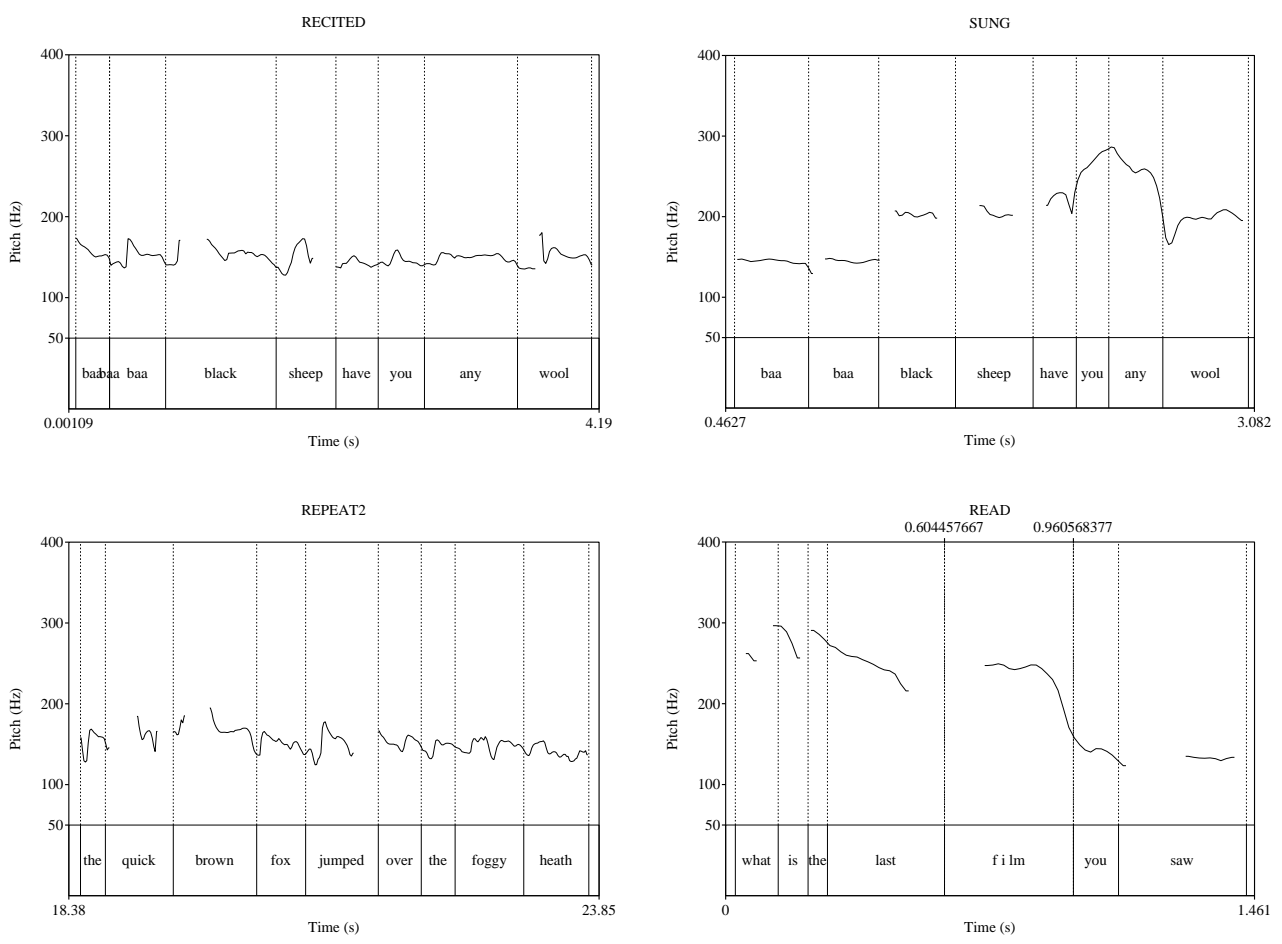

Figure 3. F0 (Hz) traces of RECITED (top left), SUNG (top right), REPEAT (bottom left) and READ (bottom right) speech

46 